\title{
Cementation of Sand Soil by Microbially Induced Calcite Precipitation at Various Degrees of Saturation
}

\author{
Liang Cheng ${ }^{1}$, Ralf Cord-Ruwisch ${ }^{2}$, Mohamed A. Shahin ${ }^{3}$
}

${ }^{1}$ Liang CHENG: Ph.D. student, School of Biological Sciences and Biotechnology, Murdoch University, South Street, Murdoch, Western Australia, 6150, Australia. Email: L.Cheng@murdoch.edu.au

${ }^{2}$ Ralf Cord-Ruwisch: Senior Lecturer, School of Biological Sciences and Biotechnology, Murdoch University, South Street, Murdoch, Western Australia, 6150, Australia. Email: R.Cord-Ruwisch@murdoch.edu.au

${ }^{3}$ Mohamed A. Shahin: Associate Professor, Department of Civil Engineering, Curtin University, Perth WA, 6845, Australia. Email: M.Shahin@ curtin.edu.au

Corresponding author: Liang CHENG: Ph.D. student, School of Biological Sciences and Biotechnology, south street campus, Murdoch University, 90 South Street, Murdoch, Western Australia, 6150, Australia. Email: L.Cheng@murdoch.edu.au \& c_howking@ hotmail.com Tel: +61-8-93602403; Fax: +61-8-93107084;

Submitted to: Canadian Geotechnical Journal 


\section{Cementation of Sand Soil by Microbially Induced Calcite 2 Precipitation at Various Saturation Degrees}

3 Liang Cheng, Ralf Cord-Ruwisch, Mohamed A. Shahin

\section{Abstract:}

5 A newly emerging microbiological soil stabilization method, known as microbially 6 induced calcite precipitation (MICP), is tested for geotechnical engineering 7 applications. MICP is a promising technique that utilizes the metabolic pathways of 8 bacteria to form calcite precipitation throughout the soil matrix, leading to an increase

9 in soil strength and stiffness. This paper investigates the geotechnical properties of a 10 sand bio-cemented under different degrees of saturation. A series of laboratory 11 experiments was conducted, including sieve analysis, permeability, unconfined 12 compressive strength, consolidated undrained triaxial, and durability tests. The results 13 indicate that higher soil strength can be obtained at similar $\mathrm{CaCO}_{3}$ content when the 14 treatment is performed under low degree of saturation. Fine sand samples exhibited 15 higher cohesion but lower friction angle than coarse sand samples with similar $\mathrm{CaCO}_{3}$ 16 content. The results also confirm the potential of MICP as a viable alternative technique 17 for soil improvement in many geotechnical engineering applications, including 18 liquefiable sand deposits, slope stabilization and subgrade reinforcement. The freeze 19 thaw and acid rain resistance of MICP treated sand has also been tested.

20 CE Database keywords: Soil stabilization; Cementation; Microorganisms; Calcium 21 carbonate; Durability. 


\section{Introduction}

23 Current soil improvement applications include soil replacement, preloading for 24 achieving consolidation, chemical admixture and grouting stabilization. These 25 techniques are time consuming, expensive and in the case of grouting and admixture 26 stabilization are environmentally detrimental (DeJong et al. 2010). In 1974 in Japan a 27 case study documented by Karol (2003) illustrated the environmental impact when 28 acrylamide grout leached into waterways causing five substantiated cases of water 29 poisoning. As a result a ban was placed on nearly all chemical grouts, further 30 reverberating to other countries to apply similar prohibition (Karol 2003). Therefore, 31 continuing studies into finding alternative soil improvement methods are vital to 32 achieve optimum performance, economic viability and environmental sustainability.

33 Calcite in-situ precipitation system (CIPS) and microbially induced calcite precipitation 34 (MICP) have been the subjects of research for several industrial applications. 35 Improvement of soil mechanical properties by MICP is currently of particular interest to engineers and microbiologists, and has been demonstrated by several researchers at

37 varying scales (DeJong et al. 2006; Whiffin et al. 2007; van Paassen et al. 2010). The 38 technique can alter the soil characteristics to increase the shear strength and stiffness, 39 while maintaining adequate permeability (Burbank et al. 2011). The technique involves 40 introducing aerobically cultivated bacteria with highly active urease enzyme into soil, 41 harnessing the urease enzyme to catalyze the hydrolysis of urea to produce ammonium 42 and carbonate ions. The chemical reaction involved in this process is shown as follows 43 (Eq. 1): 
45 In the presence of an introduced calcium source, often calcium chloride $\left(\mathrm{CaCl}_{2}\right)$, the 46 calcium carbonate $\left(\mathrm{CaCO}_{3}\right.$, calcite) forms throughout the soil matrix based on the 47 following chemical reaction (Eq. 2):

[2] $\mathrm{Ca}^{2+}+\mathrm{CO}_{3}^{2-} \rightarrow \mathrm{CaCO}_{3}(\mathrm{~s})$

The produced microbially induced $\mathrm{CaCO}_{3}$ precipitates bridge adjacent soil particles by cementing the soil grains together to form cemented sand illustrative of calcareous rock

51 (DeJong et al. 2006).

52 Controlling the MICP process and predicting the resulting material properties are 53 essential in improving the engineering properties of porous solid materials (e.g. soil). 54 Many researchers have investigated the empirical correlations between the amount of 55 precipitated $\mathrm{CaCO}_{3}$ crystals and soil engineering parameters such as the soil porosity, strength, stiffness and permeability (Ismail et al. 2002a, 2002b; Whiffin et al. 2007).

57 The initial properties of soils and the precipitated $\mathrm{CaCO}_{3}$ crystals can vary in mineral 58 type, density, shape, size distribution and texture (Mitchell and Ferris 2006; Ismail et al. 59 2002a; Warren et al. 2001), which might give an explanation for the observed 60 differences in the resulting engineering properties of MICP treated soils.

61 In a previous study carried out by Cheng and Cord-Ruwisch (2012), more effective crystals precipitating at the sand particles contact points were achieved under a low

63 degree of saturation. This suggested that by controlling the in-situ saturation conditions 64 during the MICP process, the distribution of crystals can be predominantly controlled 
65 and restricted to the inter-particle contact points. In the current paper, the feasibility of $66 \mathrm{MICP}$ as a promising ground improvement technique is evaluated via a series of

67 laboratory tests using sand columns under various saturation conditions. The laboratory

68 results demonstrate the potential of this technique for geotechnical engineering 69 applications such as preventing liquefaction and improving the stability of 70 embankments.

\section{Materials and Testing Methods}

\section{$\begin{array}{lll}72 & 2.1 & \text { Sand Soil Tested }\end{array}$}

73 Two different types of pure silica sand (Cook Industrial, Minerals Pty. Ltd. Western 74 Australia) were selected for the current study. Sieve analysis was performed for both 75 fine and coarse grained sands to determine the particle size distribution, which is one of 76 the primary components that govern the mechanical behavior of soils. The particle size 77 distribution curves of the fine and coarse sands used are shown in Figure 1. Both sands 78 are classified as poorly graded sand according to the Unified Soil Classification System 79 (USCS). Poorly graded sands were selected as they exhibit undesirable engineering 80 behavior for most geotechnical engineering applications. Both sands have a specific 81 gravity of 2.62

\subsection{Bacterial Suspension and Cementation Solution for MICP System}

83 The urease active strain of Bacillus sphaericus (MCP-11) (DSM 23526, available now 84 from DSMZ, Germany), which was isolated from the previous study (AI-Thawadi and 85 Cord-Ruwisch 2012), was used in the current experiments. The isolated strain (MCP11) 86 was cultivated under sterile aerobic batch condition in yeast extract based medium (20 

hours incubation at $28^{\circ} \mathrm{C}$, the culture was harvested and stored at $4^{\circ} \mathrm{C}$ prior to use. The optical density $\left(\mathrm{OD}_{600}\right)$ of the harvested bacterial suspension varied between 1.5 to 2.0,

90 and the urease activity was approximately $10 \mathrm{U} / \mathrm{ml}(1 \mathrm{U}=1 \mu \mathrm{mol}$ urea hydrolyzed per

91 min). The $\mathrm{CaCO}_{3}$ precipitation rate, depending on the amount of urease activity 92 introduced, can affect the size of the crystals and in turn the bonding force of the $\mathrm{CaCO}_{3}$ 93 crystal bridges and corresponding strength of the treated soil (Ismail et al. 2002a). In 94 this study, the average $\mathrm{CaCO}_{3}$ precipitation rate was about $10 \mathrm{~g} / \mathrm{L}$ (solution)/h. The 95 cementation solution consisted of $1 \mathrm{M}$ urea and $1 \mathrm{M} \mathrm{CaCl}_{2}$.

\subsection{Sample Preparation}

97 The sample preparation started with packing the dry sand (fine and coarse) into a PVC column of $160 \mathrm{~mm}$ in height and $55 \mathrm{~mm}$ inner diameter. The final dry density and

99 porosity of the sand samples were about $1.62-1.63 \mathrm{~g} / \mathrm{cm}^{3}$ and $39 \%$, respectively.

100 Various amounts of water were then flushed from top to bottom to provide the desired

101 degree of saturation within the sand matrix. The degree of saturation is the volume of 102 water in the voids, expressed as percentage of the total volume of voids, according the 103 following equation (Eq. 3):

104 [3] Saturation Degree, $S(\%)=\frac{V_{\text {water }}}{V_{\text {voids }}} \times 100$

105 where; $V_{\text {water }}$ is the volume of water in the soil matrix and $V_{\text {voids }}$ is the volume of voids.

106 Unless otherwise stated, the sample preparation consisted of the following three steps: 
107 1) Alternating injection of equal volumes of bacterial suspension and cementation 108 solution with an inflow rate of about $1 \mathrm{~L} /$ hour. The total volume of the introduced

109 solutions was the same as the aforementioned water volume so as to keep a 110 constant degree of saturation. A vacuum pump was connected to the bottom of the 111 PVC column to remove the excess solution.

112 2) Curing for 12 hours at $25 \pm 1^{\circ} \mathrm{C}$ to allow the bacterial fixation process to complete.

113 3) Percolation of cementation solution with the same flow rate followed by another 114 curing period of 12 hours at $25 \pm 1^{\circ} \mathrm{C}$. This step was carried out twice.

115 It should be noted that, to obtain different mechanical properties of the soil samples, the 116 above-mentioned three steps might be conducted more than once.

117 The key issue of the above process is to keep a constant degree of saturation throughout 118 the tests by managing the volume of extracted solution to be equal to that of the injected 119 solution. Meanwhile, to avoid solution accumulation at the bottom of the sand column 120 by gravity, the PVC columns were horizontally placed during the curing period. The 121 saturation degrees over the entire $15 \mathrm{~cm}$ long sand columns were determined. The local 122 saturation of the columns between 2.5 to $12.5 \mathrm{~cm}$ depth was relatively homogenously 123 distributed with a deviation not greater than $\pm 6 \%$ saturation. Therefore, the specimens 124 prepared for the mechanical property analyses were taken from about 2 to $13 \mathrm{~cm}$ depth 125 of the sand columns. 
127 In order to characterize the shapes and locations of the precipitated $\mathrm{CaCO}_{3}$ and to

128 investigate the bonding behaviour between the grain hosts and cement agent,

129 microscopy analysis was conducted on the cemented soil samples, which were taken

130 from the centre of the cemented sand columns. Before conducting the microscopy

131 investigation, all samples were flushed with tap water and dried at $60{ }^{\circ} \mathrm{C}$ for 24 hours.

132 The microscopy investigation was carried out using scanning electron microscopy

133 (SEM) PHILIPS XL20 Scanning Electron Microscope, Eindhoven, the Netherlands.

\section{$134 \quad 2.5 \quad$ Unconfined Compressive Strength (UCS) Tests}

135 To quantify the strength imparted into the MICP treated silica sand under different

136 saturation conditions, the unconfined compressive strength (UCS) tests were conducted

137 on cemented specimens of $55 \mathrm{~mm}$ in diameter with a selected diameter to height ratio of

$1381: 1.5$ to $1: 2$. The axial load was applied at a constant rate of $1.0 \mathrm{~mm} / \mathrm{min}$. Before

139 carrying out the tests, the sand samples were treated with different amounts of MICP

140 under $20 \%, 40 \%, 80 \%$ and $100 \%$ degrees of saturation.

\section{$141 \quad 2.6 \quad$ Triaxial Compression Tests}

142 The triaxial compression test was employed to provide verification for the MICP as a

143 soil stabilization technique. This test is considered to be the most reliable test to

144 measure the shear strength parameters of soils. In this study, a series of single-stage

145 consolidated undrained triaxial tests with pore water pressure measurement were carried

146 out to establish the effective shear strength parameters (i.e., cohesion, $c$, and friction

147 angle, $\left.\phi^{\prime}\right)$ of the bio-cemented sand. Specimens were set under one confining pressure 
148 and sheared till failure. The effective cohesion and friction angle were determined using

149 the Mohr-Coulomb failure envelopes established from three individual samples. All

150 tests were conducted in accordance with the procedures set out by Head (1998). Before

151 carrying out the triaxial tests, the bio-cemented specimens were treated at different

152 degrees of saturation of $30 \%, 65 \%$ and $100 \%$. Each triaxial test started with saturating

153 the sand specimens with tap water so as to achieve a Skempton's $B$ value of at least

$15495 \%$. The specimens were then subjected to confining pressures of 50, 100 and $200 \mathrm{kPa}$,

155 respectively, and an axial stress was then applied to failure at a strain rate of $1 \mathrm{~mm} / \mathrm{min}$.

156 All triaxial tests were performed on specimens of $55 \mathrm{~mm}$ in diameter with a selected

157 diameter to height ratio of approximately 1:2. A baseline sample of untreated sand was

158 also tested to allow comparison of the soil improvement properties.

\section{$\begin{array}{lll}159 & 2.7 & \text { Permeability Tests }\end{array}$}

160 Permeability is a primary factor that controls the behavior of porous materials under

161 saturated conditions and thus dictates the suitability of a specific material for certain

162 applications (Shahin et al. 2011). Porous materials with high permeability can prevent

163 the development of excess pore water pressure during loading. To identify the

164 permeability of cemented sand treated with different amounts of $\mathrm{CaCO}_{3}$ precipitates,

165 more samples were prepared at degrees of saturation of $30 \%, 65 \%$ and $100 \%$, and

166 permeability tests were conducted. The permeability test was also conducted on the

167 untreated samples for the purpose of comparison with the treated samples. The

168 untreated fine sand has a hydraulic conductivity of $9.2 \times 10^{-5} \mathrm{~m} / \mathrm{s}$, whereas it is $44.7 \times$

$16910^{-5} \mathrm{~m} / \mathrm{s}$ for the untreated coarse sand. 
170 Laboratory determination of the permeability of the untreated and bio-cemented sand

171 was conducted using constant head permeability test with a rigid side wall device in

172 accordance with the Australian Standards AS 1289 (2007). All specimens were

173 saturated prior to the permeability test by flushing through $2 \mathrm{~L}$ tap water under $15 \mathrm{kPa}$

174 back pressure (hydraulic head of about $150 \mathrm{~cm}$ ) to remove most of the remained pore 175 air.

176 In order to compare the permeability of the MICP improved soil with conventional soil 177 improvement using chemical additives, a series of mixtures of fine sand with various 178 proportions of Portland cement were prepared and tested for their strength and

179 permeability. The details of the Portland cement samples are listed in Table 1. The 180 mixtures were poured into PVC columns with the same dimension of that used for bio181 cementation, and a strong vibration was applied to avoid any air bubbles that might

182 remain in the mixture. The prepared mixtures were then cured at the room temperature $183\left(20 \pm 1{ }^{\circ} \mathrm{C}\right)$ for 7 days prior to the UCS and permeability measurements.

\section{$184 \quad 2.8 \quad$ Durability Tests}

\subsubsection{Freeze-Thaw Durability}

186 To test the resistance of MICP cemented samples to freeze-thaw (FT) cycling, a series

187 of fine sand samples (110 $\mathrm{mm}$ in height and $55 \mathrm{~mm}$ in diameter) treated by MICP and

188 Portland cement, as described previously, was subjected to 10 cycles of FT actions.

189 Each cycle test involves subjecting the samples to a 12-hour freeze at $-14{ }^{\circ} \mathrm{C}$ followed

190 by a 12 -hour thaw under ambient conditions $\left(20 \pm 1{ }^{\circ} \mathrm{C}\right)$. All samples were immersed in 191 water throughout the cycling FT testing. 
193 Artificial acid rain was made according to Haneef et al. (1992) and the final pH of acid

194 rain was adjusted to 3.5 by adding additional $\mathrm{H}_{2} \mathrm{SO}_{4}$. The artificial acid rain was

195 injected from the top of the cemented fine sand columns $(180 \mathrm{~mm}$ in height and $55 \mathrm{~mm}$

196 in diameter) with a flow rate of approximately $3 \mathrm{~mL} / \mathrm{min}$. The weight of the sand

197 column was measured periodically, after it was washed by DI water and dried at $105{ }^{\circ} \mathrm{C}$

198 for 12 hours. All samples were cut in half prior to the shear strength test and the

199 strength of the top and bottom parts of the sand samples (eroded and un-eroded) was

200 recorded.

\section{Presentation of Results}

202

203

\subsection{Effect of Degree of Saturation on UCS Results of MICP Cemented Coarse} Sand

Figures 2 and 3 show the results of the UCS tests carried out on the coarse sand treated with different amounts of MICP under various saturation degrees of $20 \%, 40 \%, 80 \%$ and $100 \%$. It can be seen that both unconfined compressive strength $\left(q_{u c s}\right)$ and stiffness (or elastic modulus, $E$ ) increase with the increase of $\mathrm{CaCO}_{3}$ content for all treated samples. Both $q_{u c s}$ and $E$ follow exponential relationships with the content of $\mathrm{CaCO}_{3}$, which are in line with previous results reported by van Paassen et al. (2010). It can also be seen that for the same amount of $\mathrm{CaCO}_{3}$ precipitation, both $q_{u c s}$ and $E$ increase with the reduction in the degree of saturation. Saturation degree higher than $80 \%$ was found to have little impact on $q_{u c s}$ and $E$ of MICP treated coarse sands. 
213 It is worthwhile mentioning that the failure mechanism of the cemented sand was

214 different from the strong to the weak samples. In the weak samples, the broken cores

215 completely lost strength at the grain scale around the failure plane, or through the entire

216 sample when the failure planes were not clear. This was consistent with previous

217 observation by van Paassen et al. (2009). In the strong samples, however, tensile cracks

218 appeared vertically from top to bottom along the sample and the failure planes can be

219 distinguished clearly, which was also similar to the previous observation by van

$220 \quad$ Paassen et al. (2009).

221 It is of interest to examine the location of MICP treated coarse silica sand in the

222 spectrum of other geomaterials in terms of the relationship between $E$ and $q_{u c s}$, as shown

223 in Figure 4. The change in the rigidity of the MICP treated silica sand is also shown in

224 Figure 5 (rigidity $=E / q_{u c s}=1 / \varepsilon_{f}$, where $\varepsilon_{f}$ is the axial strain at failure). It can be seen that

225 the rigidity increases (in an exponential law fashion) with increase of $\mathrm{CaCO}_{3}$ content,

226 but was independent of the degree of saturation. It can also be seen that at similar

227 amount of $\mathrm{CaCO}_{3}$, the rigidity of the samples cemented at lower degree of saturation

228 was higher than that of the samples treated with higher degree of saturation. Similar to

229 the effect of saturation on $q_{u c s}$, a degree of saturation higher than $80 \%$ had marginal

230 impact on the rigidity of MICP cemented sand for certain amount of $\mathrm{CaCO}_{3}$ content.

\subsection{Microscopy Images of MICP Cemented Sand at $20 \%$ and $100 \%$ Saturation}

232 In this part, an attempt is made to investigate the reason for increasing strength and

233 stiffness of the MICP treated sand at lower degree of saturation. It is believed that the

234 micro-features of precipitated crystals around the sand grains and the creation of hinges

235 can be responsible for the different mechanical responses of MICP treated porous 
materials obtained at different saturation conditions (Paraskeva et al. 2000). In order to investigate this matter, the micro-structure of the treated sands was investigated through the microscopy images shown in Figures 6 and 7 for soil treated at degrees of saturation of $100 \%$ and $20 \%$, respectively.

240 It can be seen from the images shown in Figure 6 that the $\mathrm{CaCO}_{3}$ crystals produced at $241100 \%$ saturation take rhombohedron form in which the agglomerated rhombohedral 242 crystals precipitate not only in the inter-particle contact points but also on the grain surface, or suspend in the pore spaces, leading to insufficient connections between the sand grains. For the sand treated at $20 \%$ saturation (Figure 7), a strong coating effect of the MICP process is predominant. This coating effect is likely attributed to the homogeneously adsorbed solution on the sand grains surface due to the surface tension

247 force, which allows the MICP solution to access the full surface of the grains. One important feature that can be derived from Figure 7 is that the gaps between the host grains are almost completely filled with crystals, which is likely due to the fact that the retained MICP solution located between the grains takes a menisci form, where the crystals are produced and precipitated out of the aqueous solution to fill the gaps. This

252 feature may affect the adhesion mechanism amongst the host grains and, consequently, 253 the mechanical behavior of the entire soil matrix.

254 It should be noted that both samples treated at 100\% saturation (Figure 6) and 20\% saturation (Figure 7) demonstrate similar $q_{u c s}$ of $1 \mathrm{MPa}$ and $1.14 \mathrm{MPa}$, respectively,

256 but they differ in the $\mathrm{CaCO}_{3}$ content. It is apparent that the development of the $\mathrm{CaCO}_{3}$ 257 at the contact boundary is vastly different in both cases, and in comparison it can be identified that an excess precipitation of the $\mathrm{CaCO}_{3}$ at the sand grain boundary exists for 
259 the case of $100 \%$ saturation condition. As a result, the sample treated at $20 \%$ saturation

260 contained fewer $\mathrm{CaCO}_{3}$ crystals less than half of that precipitated at $100 \%$ saturation

261 (i.e. $0.143 \mathrm{~g} / \mathrm{g}$ sand). This indicates that the mechanical strength of the MICP treated

262 samples is due to the effectiveness of $\mathrm{CaCO}_{3}$ formation that precipitated in the inter-

263 particles contact points, rather than the total amount of the $\mathrm{CaCO}_{3}$ crystals formed.

264 The schematic diagram shown in Figure 8 can provide further explanation of the

265 previous observation. For partially saturated condition, the air occupies the center of the

266 pores and the total surface of the grains is covered with adsorbed solution, which is

267 predominantly concentrated at the inter-particles connection points (corner) forming

268 menisci shape (Tuller et al. 1999). Therefore, the crystal precipitation has mainly

269 occurred at the contact points of the grains (Figure 8), which contributes to the strength

270 improvement. In the case of full saturation, as the MICP solution occupies the entire

271 pore space, the crystals are free to precipitate without being restricted to the size and

272 location, resulting in the agglomerated crystals to be formed on both the host grain

273 surface and grain gaps. From the above discussion, it can be stated that the crystals

274 formation varies in size and location according to the distribution of pore solution,

275 which is influenced by the saturation conditions.

\section{$276 \quad 3.3 \quad$ Mathematical Model of Total Volume of Effective Hinges}

277 In Sections 3.2 and 3.3, it was experimentally shown (through microscopy images and

278 results of UCS tests) that the degree of saturation at which a sand soil is treated by

279 MICP has a significant impact on the resulting strength and stiffness. Also the particle

280 size of the constituent soil affects the cementation process, because it has a significant

281 impact on the retained pore water in terms of the content, shapes and distribution under 
282 various saturation conditions, consecutively on the cementation process. In this section, 283 a mathematical model is developed in order to measure the impact of the saturation 284 degree and particle size on the effective "hinge" formation within a soil matrix treated 285 with MICP.

286 In order to develop the mathematical model, a soil matrix with uniform spherical 287 particles is assumed. All spherical particles are packed in a tetrahedral packing form 288 having the closest packing order with a void ratio of 0.34 . The total volume of the sand 289 matrix $(V)$ and void volume $\left(V_{\text {void }}\right)$ can be approximately calculated as follows:

$290 \quad[4] \quad V=N \times(4 / 3) \times \pi \times R^{3} /(1-0.34)$

$291 \quad[5] \quad V_{\text {void }}=0.34 \times V$

292 where; $N$ is the number of particle spheres and $R$ is the radius of the sphere (see Figure $2939)$.

294 In the assumed tetrahedral packing, each particle has 12 contact points with the 295 surrounding particles and there are 6 full water lenses in each unit volume of $5.66 R^{3}$ (Lu 296 and Likos 2004). The total number of water lenses $\left(N_{l e n s}\right)$ in the sand matrix therefore 297 can be calculated as follows: $N_{\text {lens }}=6 \times V /\left(5.66 \times R^{3}\right)$

299 The crystals are assumed to be homogeneously precipitated on the surface of spheres, 300 where the water lenses are attached, and the crystal "hinges" formed in point-to-point 
301 contacts contribute to the bonding force. In general, it is reasonable to make the 302 hypothesis that the bigger volume of "hinges" causes stronger bonding force. From 303 Figure $9 \mathrm{~b}$, the total volume of effective hinges $\left(V_{\text {T-hinges }}\right)$ in the soil matrix can be 304 calculated as follows:

305 [7] $\quad V_{T \text {-hinges }}=N_{\text {lens }} \times V_{\text {hinge }}=N_{\text {lens }} \times\left(2 \pi \times r^{2} h^{\prime}-2 \pi / 3 \times h^{\prime 2}\left(3 r-h^{\prime}\right)\right)$

306 where; $V_{\text {hinge }}$ presents the volume of each hinge, and $h^{\prime} \& r$ are as illustrated in Figure $3079 \mathrm{~b}$, which can be obtained based on the following geometric calculations:

$308 \quad[8] \quad h^{\prime}=R-\sqrt{R^{2}-r^{2}}$

$309 \quad[9] \quad r=\sqrt{(R+h)^{2}-R^{2}}$

310 In Eqns. 8 and 9, $h$ is the thickness of crystals on each sphere and can be estimated as 311 follows:

$312[10] \quad h=V_{\text {crystals }} /\left(2 \times S_{\text {surface }}\right)$

313 where; $V_{\text {crystals }}$ is the volume of $\mathrm{CaCO}_{3}$ crystals precipitated on each sphere and $S_{\text {surface }}$ is 314 the contact surface between the water lens and the sphere (see Figure 9a and b). Both $315 V_{\text {crystals }}$ and $S_{\text {surface }}$ can be calculated according to the following expressions:

$316 \quad[11] \quad V_{\text {crystals }}=C_{\text {crystals }} \quad V /{ }_{\text {crystal }} / N_{\text {lens }}$

$317 \quad[12] \quad S_{\text {surface }}=2 \pi \times(R+h)^{2} \times(R-(R+h) \times \cos (\theta))$ 
318 where; $C_{\text {crystals }}$ is the $\mathrm{CaCO}_{3}$ crystals content $\left(\mathrm{g} / \mathrm{cm}^{3}\right)$ and $\rho_{\text {crystals }}$ is density of $\mathrm{CaCO}_{3}$

319 crystals (i.e. $2.71 \mathrm{~g} / \mathrm{cm}^{3}$ ).

320 The degree of saturation of the soil matrix can also be obtained as follows:

321

[13] $\quad S_{\text {saturation }} \%=V_{\text {water }} / V_{\text {void }}=N_{\text {lens }} \times V_{\text {lens }} / V_{\text {void }}$

322 where; $V_{\text {lens }}$ is the volume of each water lens, which can be calculated in accordance

323 with Dallavalle (1943), as follows:

324

[14] $\quad V_{\text {lens }}=2 \pi \times R^{3} \times(1 / \cos (\theta)-1)^{2} \times[1-(\pi / 2-\theta) \times \tan (\theta)]$

325 The developed mathematical model (i.e. Eqns. 7 and 14) was used to illustrate the 326 dependency of the total volume of effective "hinges" formed in the same volume of sand matrixes on the degree of saturation and particle size (see Figure 10). The number of spherical particles, $N$, is inversely proportional to the particle size $(R)$, providing the same total matrix volume. This means that if the coarse sand particle has a radius $R$

330 while the fine sand particle has a radius $R / 2$, the number of particles of the fine sand 331 will be eight times that of the coarse sand. Consequently, the total number of water 332 lenses $\left(N_{\text {lens }}\right)$ in the fine sand matrix will be eight times that of the coarse sand.

333 The model predictions shown in Figure 10 indicate that a greater volume of effective 334 hinges is formed in the fine sand compared to the coarse sand having similar amount of $335 \mathrm{CaCO}_{3}$ precipitation, indicating that the strength is improved with the decrease in 336 particle size. This model also derives that a lower degree of saturation leads to a greater 337 number of effective hinges at the same $\mathrm{CaCO}_{3}$ content and consequently an improved 
338 mechanical behavior (i.e. UCS). The model predictions are supported by the previous experimental UCS tests and microscopy images of the coarse sand.

340 To further investigate the real effect of particle size and degree of saturation on the

341 shear strength parameters of treated sand (i.e., cohesion, $c^{\prime}$, and friction angle, $\phi^{\prime}$ ),

342 which are more relevant to most geotechnical engineering applications, the results of the

343 undrained triaxial tests are presented below.

\section{$344 \quad 3.4$ Mechanical Behavior of Stabilized Sand in Triaxial Tests}

345 The effective shear strength parameters (i.e. cohesion, $c^{\prime}$, and friction angle, $\phi^{\prime}$ ) of the 346 silica sand treated with different amounts of $\mathrm{CaCO}_{3}$ were determined from the Mohr-

347 Coulomb envelopes. These were developed from the peak shear stress values obtained

348 from the triaxial tests. Results are shown in Figures 11 and 12, for coarse and fine 349 sands, respectively.

\section{$350 \quad$ Coarse Sand}

351 Figure 11 shows that both the cohesion, $c^{\prime}$, and friction angle, $\phi^{\prime}$, increase with the 352 increase of the $\mathrm{CaCO}_{3}$ content at all degrees of saturation. At a fixed amount of $\mathrm{CaCO}_{3}$ 353 a lower saturation degree increased the $c^{\prime}$ and $\phi^{\prime}$ values compared to those at higher 354 saturation degrees. Under lower saturation degree condition, the precipitated crystals 355 contributed more to improving cohesion than to improving friction angle. At higher 356 saturation degrees of $65 \%$ and $100 \%$, the impact on improving the friction angle was 357 even less. As mentioned earlier, the effect of degree of saturation on improving the 358 shear strength behavior of soil and thus the shear strength parameters is attributed to 
359 restricting the crystal formation mainly to the connection points. The well-placed 360 crystals are efficient in increasing the inter-particle connection, thereby, enhancing the

361 soil cohesion and friction angle. The increase in both cohesion and friction angle at

362 higher $\mathrm{CaCO}_{3}$ content that has occurred regardless of the saturation degree is likely due

363 to the fact that precipitated crystals start filling the pore spaces. One important feature

364 that can be derived from Figure 11 is that at low $\mathrm{CaCO}_{3}$ content the friction angle had 365 only marginally increased under all saturation conditions, which was probably due to

366 the slight increase in the dry density. The optimum condition for $c^{\prime}$ and $\phi^{\prime}$ has occurred 367 at the saturation condition of $30 \%$.

368 Fine Sand

369 Figure 12 shows that the overall correlation between the shear strength parameters and 370 the $\mathrm{CaCO}_{3}$ content at different saturation degrees is similar to that of the coarse sand.

371 By comparing the results of the two sands used, it can be concluded that under the same 372 saturation condition, the coarse sand demonstrates higher friction angle than the fine 373 sand at similar $\mathrm{CaCO}_{3}$ content. The fine sand with similar $\mathrm{CaCO}_{3}$ content showed 374 significantly higher values of cohesion compared to the coarse sand. This can be 375 explained as follows. Smaller particles have two effects including: (a) providing more 376 inter-particle contact points for microbially induced $\mathrm{CaCO}_{3}$ to precipitate; and (b) 377 reducing the stress acting per particle contact. MICP acts most efficiently at a particle 378 contact just as cementation begins, and continued expansion of cementation around a 379 particle contact has decreased effect. Therefore, reallocating the $\mathrm{CaCO}_{3}$ crystals to two 380 contact locations instead of one would be more effective. At the same time, the contact stress decreases as a function of the particle radius squared. Therefore, smaller particles 
382 provide two compounding benefits: (1) more efficient MICP; and (2) lower particle contact stresses.

\subsection{Effect of MICP Treated Sand on Permeability}

385 Figure 13 shows the results of permeability tests conducted in the current study. It can

386 be seen that a reduction in permeability was encountered for all bio-cemented sand 387 samples. In contrast to the phenomenon reported by Whiffin et al. (2007), the 388 permeability decreased with an increase in $\mathrm{CaCO}_{3}$ content for both fine and coarse 389 sands, irrespective of the saturation degree. Results suggest that it is preferable to 390 conduct the MICP process under lower saturation conditions, as it enabled improved 391 mechanical behavior at the same time as maintaining relatively high residual 392 permeability.

393 Figure 14 shows the results of comparison between sand samples treated with Portland

394 cement and bio-cement. It can be seen that the bio-cement samples have higher strength

395 in the range of lower cement agents content $(<0.1 \mathrm{~g} / \mathrm{g}$ sand $)$ compared to the Portland 396 cement samples after 7 days of curing. However, this comparison would differ 397 depending on the applied curing time of the Portland cement samples. The permeability 398 of the biocementation samples is significantly higher than that of the Portland cement 399 samples. As an example, a mixture with $7 \%(0.07 \mathrm{~g} / \mathrm{g}$ sand $)$ Portland cement 400 dramatically decreased permeability by $98 \%$. Cement content higher than $9.6 \%(0.096$ $401 \mathrm{~g} / \mathrm{g}$ sand) produced a poor drainage material with permeability less than $1 \times 10^{-6} \mathrm{~m} / \mathrm{s}$. 402 The significant loss of permeability in the Portland cement samples is due to the 403 occupation of the pore space by the water insoluble hydrates formed from the cement 404 hydration reaction with the pore water. In contrast, the loss of permeability in bio- 
cement samples is caused by the pore spaces becoming occupied by the calcite crystals, which only causes a smaller volume change compared to the hydrates.

407 From the previous results, it can be concluded that apart from the significant increase in 408 soil strength and stiffness, one advantage of biocementation is attributed to the relative 409 ability to retain soil permeability after treatment, compared to the traditional chemical 410 treatment by Portland cement.

\subsection{Effect of MICP Treatment on Sand Freeze-Thaw Durability}

412 Destruction of porous materials caused by freezing and thawing has been of great 413 concern to engineers for more than 200 years (Johnson 1952). The phase change of

414 water adsorbed in the soil pores is the most significant cause of deterioration of exposed 415 porous materials. Porous solids with high porosity or permeability usually have a good 416 service record after free-thaw (FT) action (Litvan 1980). Indicated by the previous 417 permeability results, the sand samples treated with MICP have a high residual 418 permeability, which may favor the samples to endure the cycled FT action.

419 By comparing the UCS of MICP tested samples before and after FT cycling, less than $42010 \%$ decrease in strength occurred irrespective of the treatment conditions (Figure 15).

421 The severity of the mechanical damage is proportional to the water content of the porous solid (Litvan 1980); however, the high porosity and permeability allow more rapid water mass transfer in the sand matrix, which can increase the FT resistance. For

424 MICP samples, the crystals formed at the contact points can maintain the connection of 425 pores without restricting the pore water mobility, which is also proved by the previous 
426 permeability tests. For the Portland cement samples, the FT cycles caused serious 427 damage, as expected, with about $40 \%$ decrease in strength.

\subsubsection{Acid Rain Erosion Durability}

429 Acid rain is detrimental to many construction materials, particularly those made from

430 limestone or sand stone with high $\mathrm{CaCO}_{3}$ content. The chemical reaction between the 431 calcium carbonate and sulfuric acid (the primary acid component of acid rain) causes

432 the dissolution of $\mathrm{CaCO}_{3}$, resulting in destruction of such materials. In the MICP treated sand, the strength of sand matrix is the result of the sand particles bonded by the

434 bridging $\mathrm{CaCO}_{3}$ crystals. Therefore, the $\mathrm{CaCO}_{3}$ crystals eroded by the acid rain will 435 result in destruction of the connections between the sand particles, leading to severe 436 damaging in mechanical properties.

437 In order to test erosion and residual strength of the MICP treated sand samples after 438 exposure to the acid rain, in time mass detection of the sand matrix and UCS tests were 439 carried out and the results are presented in Figure 16. It can be seen that, as expected, 440 the artificial acid rain $(\mathrm{pH}=3.5)$ continuously eroded the biocement samples, resulting in 441 a loss of weight. The $\mathrm{pH}$ of the effluent stayed around 7.5, which indicated that the 442 protons $\left(\mathrm{H}^{+}\right)$in the acid rain were consumed by reacting with $\mathrm{CaCO}_{3}$, similar to the acid 443 rain erosion of limestone and marble. After flushing $12 \mathrm{~L}$ of acid rain through the sand 444 column, corresponding to 5 years of rainfall $(1000 \mathrm{~mm} / \mathrm{year})$, the UCS results of the 445 eroded samples reflected that no obvious damage occurred at the bottom part of the 446 sand column $(9-18 \mathrm{~cm})$. However, the strength of the top part of the sand column was 447 decreased by about $40 \%$, as shown in Figure 16. As the effect of the acid rain is chronic 
and long-term acidification results from years of acidic rainfall, a long-term simulation experiment (decades) is worthwhile to carry out in the future.

\section{Discussion}

451 This study verified that the bio-cementation technology applied to partially saturated soils lead to improved mechanical behavior of MICP treated soil matrix in terms of cohesion, friction angle and UCS, with fewer calcite crystals compared to MICP at fully saturated condition. In other words, to produce similar soil strength, partially saturated soils require fewer crystals, enabling bio-cemented soils to be produced more economically due to lower requirement for the urease enzyme, urea and $\mathrm{CaCl}_{2}$. To this end, the technique can be applied to many geotechnical-engineering applications in both fully and partially saturated conditions. In wet fully saturated condition, MICP solution is introduced into the soil by saturated flow (van Paassen et al. 2010; Whiffin et al.

460 2007). In dry or partially saturated condition, MICP solution can be introduced by 461 surface percolation and the excess of MICP solution moves deeper into the soil pores, which allows the retained MICP solution to accumulate at the connection points as a meniscus shape (Cheng and Cord-Ruwisch 2012). The restricted distribution of MICP

464 solution enables the crystals formed at the particular position, which contributes the 465 most to strength development. However, an obvious main challenge for MICP treatment 466 under unsaturated conditions is achieving homogenous distribution of $\mathrm{CaCO}_{3}$ and 467 strength, which will be investigated in subsequent phase of this work.

468 A principal engineering problem produced by current available soil improvement methods is the tendency of significantly decreasing permeability of treated soils. For 
example, the reduction in permeability due to grouting ranges between 2 and 3 orders of magnitude (Karol 2003). Consequently, the reduction in permeability disturbs natural

472 groundwater flow paths, permits the increase of pore water pressure in the soil, thus 473 increasing the risk of failure in both earth and foundation structures. The ability of 474 MICP to retain high permeability conditions is a clear advantage compared to the 475 alternative of using Portland cement. A reduction in the cost of construction and 476 installation of drainage systems would be apparent, as fewer systems would need to be 477 integrated than those typically utilizing traditional cementing agents. Another advantage 478 of MICP and its retention of in-situ permeability during bio-cementation application is 479 that it will permit additional applications of treatment allowing engineers to control the 480 final strength.

481 Engineering examples of the utilization of MICP and the associated benefits of 482 permeability retention would be in the reinforcement of transport subgrades and 483 embankments. During subgrade construction it is important to provide adequate 484 drainage at all times to prevent water from standing on the subgrade. Therefore, soil 485 stabilization by MICP technique with the capability of high permeability retention 486 would eliminate the need for additional drainage systems. Due to the minimal 487 interference with soil material hydrology, embankments strengthened with MICP will 488 have the potential to allow immediate dissipation of excess pore water pressures caused 489 by operational surcharge loads.

490 Geotechnical engineering structures exposed to dynamic loads associated with 491 earthquakes under saturated conditions can be subject to significant structural damage. 492 In this case, the soil loses most of its static strength and significant deformations occur. 
493 When such deformations are large, soils liquefy (Cornforth 2005). The soil types most 494 susceptible to liquefaction are loose granular sands that have no cementation between

495 the soil grains. Given the improvements in the undrained shear strength of sands trialed 496 in this study, MICP can be used as a viable solution to improve the properties of un497 cemented granular soils by creating cemented zones that will be no longer liquefiable.

\section{Conclusions}

499 This paper has investigated the influence of degree of saturation and soil particle size on

500 the mechanical response of calcite bio-cemented silica sand. Samples examined under

501 SEM indicated different patterns of calcite precipitation for each degree of saturation, with fully saturated condition forming agglomerated rhombohedral crystals scattered on the sand grain surface. The lower saturated conditions formed strong calcite coating on

504 the host grains and bridging between sand grains. A mathematical model has been also 505 developed, which measures the impact of the degree of saturation and particle size on 506 the effectiveness of $\mathrm{CaCO}_{3}$ precipitates in MICP treated soils.

507 Findings of this study confirmed that higher strengths were obtained at lower saturation 508 degrees, challenging most studies on MICP so far, in which biocementation was 509 performed under fully saturated condition. This important finding indicates that 510 optimum performance of this stabilization process can be achieved with lower costs, 511 making it economically viable while reducing the need for water and chemicals, hence,

512 becoming more environmentally sustainable than formerly believed.

513 The results from the durability tests have shown that MICP produced cemented samples

514 with highly durable resistance to freeze-thaw erosion, and resistless to the acid rain 
515 erosion. Both the permeability and shear strength of bio-cemented soils displayed

516 results that would support the MICP as a promising soil improvement technique. MICP

517 has been approved to be a viable alternative for engineering soil improvement

518 applications such as soil embankments, liquefiable sand deposits and subgrade

519 reinforcement.

520 The results obtained from the UCS and triaxial tests have shown that, despite having the

521 same amount of calcite crystals, the engineering response of treated sand varies

522 significantly, mainly because of the different location of the calcite deposited. The

523 calcite crystals formed under lower degree of saturation showed that more crystals are

524 formed in the contact points, which contributed to the strength of the cemented samples.

\section{Acknowledgement}

526 The authors would like to acknowledge Deltares (the Netherlands) and University of

527 Murdoch (Australia) for the financial support given to this project. The authors would

528 also like to thank Atticus Dekuyer for providing assistance in the triaxial measurements.

5297 References

530 Australian Standards AS 1289, 2007. Method of testing soils for engineering purposes.

531 Al-Thawadi, S., and Cord-Ruwisch, R. 2012. Calcium carbonate crystals formation by

532 ureolytic bacteria isolated from Australian soil and sludge. Journal of Advance Science

533 and Engineering Research, 2 (1): 13-26.

534 Barla, M., Barla, G., Lo Presti, D.C.F., Pallara, O., and Vandenbussche, N. 1999.

535 Stiffness of soft rocks from laboratory tests. Proceedings of the IS Torino '99, 2nd

536 International Symposium on Pre-failure deformation characteristics of 
538 Burbank, M.B., Weaver, T.J., Green, T.L., Williams, B.C., and Crawford, R.L. 2011.

539 Precipitation of calcite by indigenous microorganisms to strengthen liquefiable soils.

540 Geomicrobiology Journal, 28(4): 301-312.

541 Cheng, L., and Cord-Ruwisch, R. 2012. In-situ soil cementation with ureolytic bacteria 542 by surface percolation. Ecological Engineering, 42: 64-72.

543 Cornforth, D.H. 2005. Landslides in practice: investigation, analysis, and $544 \mathrm{remedial} /$ preventative options in soils. John Wiley \& Sons, Inc.

545 Dallavalle, J.M. 1943. Micrometrics. Pitman, London.

546 DeJong, J. T., Fritzges, M. B., and Nusslein, K., 2006. Microbially Induced

547 Cementation to Control Sand Response to Undrained Shear. Journal of Geotechnical 548 and Geoenvironmental Engineering, 132 (11): 1381- 1392.

549 DeJong, J. T., Mortensen, B. M., Martinez, B. C., and Nelson, D. C. 2010. Biomediated 550 soil improvement. Ecological Engineering, 36 (2): 197-210.

551 Haneef, S.J., Dickinson, C., Johnson, J.B., Thompson, G. E., and Wood, G.C. 1992. 552 Simulation of the degradation of coupled stones by artificial rain. Studies in 553 Conservation, 37(2): 105-112.

554 Head, K.J.H. 1998. Manual of Soil Laboratory Testing. John Wiley and Sons, 555 Chichester, England.

556 Ismail, M.A., Joer, H.A., Randolph, M.F., and Meritt, A. 2002a. Cementation of porous 557 materials using calcite. Géotechnique, 52(5): 313-324.

558 Ismail, M.A., Joer, H.A., Sim, W. H., and Randolph, M.F. 2002b. Effect of cement type 559 on shear behavior of cemented calcareous soil. Journal of Geotechnical and 560 Geoenvironmental Engineering, 128(6): 520-529.

561 Johnson, A.W. 1952. Frost action in roads and airfield-a review of the literature. Special 562 Report No. 1, Highway research board, Washington, D.C. 
563 Karol, R. H. 2003. Chemical Grouting and Soil Stabilization. New York, Marcel 564 Dekker.

565 Litvan, G.G. 1980. Freeze-thaw durability of porous building materials, durability of 566 building materials and components. ASTM STP 691. P. J. Sereda and G. G. Litvan, 567 Eds, American Society for testing and materials, 1980, pp. 455-463.

568 Lu, N., and Likos, W.J. 2004. Unsaturated soil mechanics. John Wiley \& Sons, Inc. 569 New Jersey.

570 Mitchell, A., and Ferris, F. 2006. The influence of bacillus pasteurii on the nucleation 571 and growth of calcium carbonate. Geomicrobiology Journal, 23(3-4): 213-226.

572 Paraskeva, C.A., Charalambous, P.C., Stokka, L.E., Klepetsanis, P.G., Koutsoukos, 573 P.G., Read, P., Ostvold, T., and Payatakes, A.C. 2000. Sandbed consolidation with 574 mineral precipitation. Journal of Colloid and Interface Science, 232: 326-339. 575 doi:10.1006/jcis.2000.7161

576 Shahin, M.A., Mardesic, T., and Nikraz, H.R. 2011. Geotechnical characteristics of 577 bauxite residue sand mixed with crumbed rubber from recycled car tires. Journal of 578 GeoEngineering, 6(1): 63-72.

579 Tuller, M., Or, D., and Dudley, L.M. 1999. Adsorption and capillary condensation in 580 porous media: liquid retention and interfacial configurations in angular pores. Water 581 Resource Research, 35 (7): 1949-1964.

582 van Paassen, L.A., Ghose, R., Van der Linden, T.J.M., Van der Star, W.R.L., and Van 583 Loosdrecht, M.C.M. 2010. Quantifying biomediated ground improvement by ureolysis: 584 large-scale biogrout experiment. Journal of Geotechnical and Geoenvironmental Engineering, 585 136(12): 1721-1728.

586 van Paassen, L.A., van Lossdrecht M.C.M., Pieron, M., Mulder,A., Ngan-Tillardm 587 D.J.M., and van der Linden, T.J.M. 2009. Strength and deformation of biologically 588 cemented sandstone. proceedings of the ISRM Regional conference EUROCK 2009589 Rock engineering in difficult ground conditions- Soft rocks and karst, 29-31 October 590 2009, Dubrovnik, Croatia, pp. 405-410. 
591 Warren, A.A., Maurice, P.A., Parmar, N., and Ferris, F.G. 2001. Mirobially mediated 592 calcium carbonate precipitation: Implications for interpreting calcite precipitation and 593 for solid-phase capture of inorganic contaminants. Geomicrobiology journal, 18(1): 93594115.

595 Whiffin, V.S., van Paassen, L.A., and Harkes, M.P. 2007. Microbial carbonate 596 precipitation as a soil improvement technique. Geomicrobiology Journal, 24(5): 417597423. 
Table 1. Mix proportions of Portland cement samples.

\begin{tabular}{ccccc}
\hline Mix ID & Cement $(\mathbf{g})$ & Sand $(\mathbf{g})$ & Water $(\mathbf{m L})$ & Density $\left(\mathbf{g} / \mathbf{c m}^{\mathbf{3}}\right)$ \\
\hline $\mathbf{1}$ & 40 & & & \\
$\mathbf{2}$ & 56 & 580 & 124 & $1.93 \pm 0.01$ \\
$\mathbf{3}$ & 72 & & & \\
$\mathbf{4}$ & 84 & & & \\
\hline
\end{tabular}

599 
600

601

602

603

604

605

606

607

608

609

610

611

612

613

614

615

616

617

618

619

620

621

622

623

624

625

626

627

628

629

630

631

632

633

634

\section{Figure Captions:}

Figure 1. Grain size distribution curves for the sand used.

Figure 2.Variation of UCS with $\mathrm{CaCO}_{3}$ content and different saturation conditions for coarse sand.

Figure 3. Variation of stiffness with $\mathrm{CaCO}_{3}$ content and different saturation conditions for coarse sand.

Figure 4. Relationship between elastic modulus $(E)$ and $q_{u c s}$ of the MICP treated silica sand compared with other geomaterials.

Figure 5. Relationship between rigidity and $\mathrm{CaCO} 3$ content for silica sand treated with MICP under different water saturation degree conditions.

Figure 6. Formation of $\mathrm{CaCO}_{3}$ crystals for samples treated at $100 \%$ saturation (note: $\mathrm{CaCO}_{3}$ content $=0.143 \mathrm{~g} / \mathrm{g}$ sand, $\mathrm{UCS}=1 \mathrm{MPa}$ ).

Figure 7. Formation of $\mathrm{CaCO}_{3}$ crystals for samples treated at $20 \%$ saturation (note: $\mathrm{CaCO}_{3}$ content $=0.057 \mathrm{~g} / \mathrm{g}$ sand, $\mathrm{UCS}=1.14 \mathrm{MPa}$ ).

Figure 8. Conceptual illustration of pore cementation solution distributed in the sand matrix under different saturation conditions.

Figure 9. Schematic diagram of two-dimensional meniscus between spherical particles: (a) water lens between two particles; and (b) simple two-dimensional geometrical illustration of hinge formation between two particles.

Figure 10. Results of mathematical model showing the correlation of the $\mathrm{CaCO}_{3}$ content and volume of effective hinges within the soil matrix for coarse and fine sands $\left(\mathrm{R}_{\mathrm{CS}}\right.$ and $\mathrm{R}_{\mathrm{FS}}$ represent the radii of the coarse and fine particles, $\mathrm{N}$ represents the number of particle spheres.).

Figure 11. Effect of saturation conditions on shear strength parameters of coarse silica sand having different amount of $\mathrm{CaCO}_{3}$.

Figure 12. Effect of saturation conditions on shear strength parameters of fine silica sand having different amount of $\mathrm{CaCO}_{3}$.

Figure 13. Permeability of cemented sand columns treated at different saturation conditions for: (a) coarse sand; and (b) fine sand.

Figure 14. UCS and permeability of sand samples cemented with bio-cement $\mathrm{CaCO}_{3}$ (100\% saturation) and Portland cement.

Figure 15. UCS of cemented fine sand samples before and after 10 cycles of FreezeThaw (FT) action (one cycle per day). (Note: $\mathrm{CaCO}_{3}$ content was about 0.06-0.065 g/g sand and Portland cement content was $0.096 \mathrm{~g} / \mathrm{g}$ sand). 
635 Figure 16. UCS and loss of weight of MICP cemented fine sand samples during the 636 acid rain erosion experiments (Note: sand columns were treated under fully saturated 637 condition with $\mathrm{CaCO}_{3}$ content of about $0.1-0.105 \mathrm{~g} / \mathrm{g}$ sand). 
Fig. 1

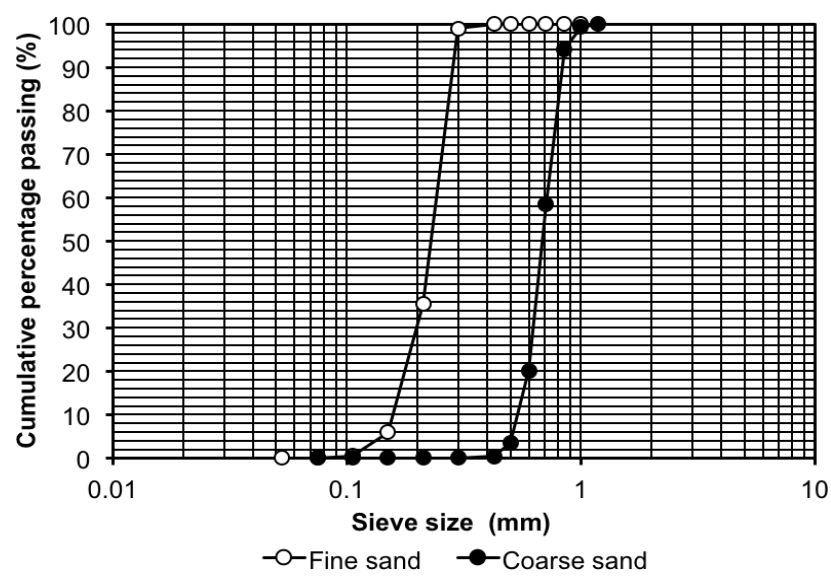


Fig. 2

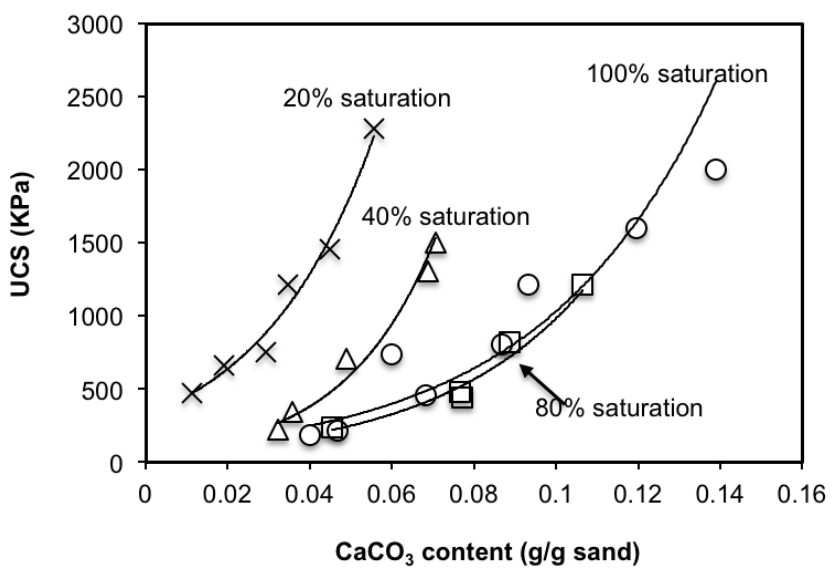


Fig. 3

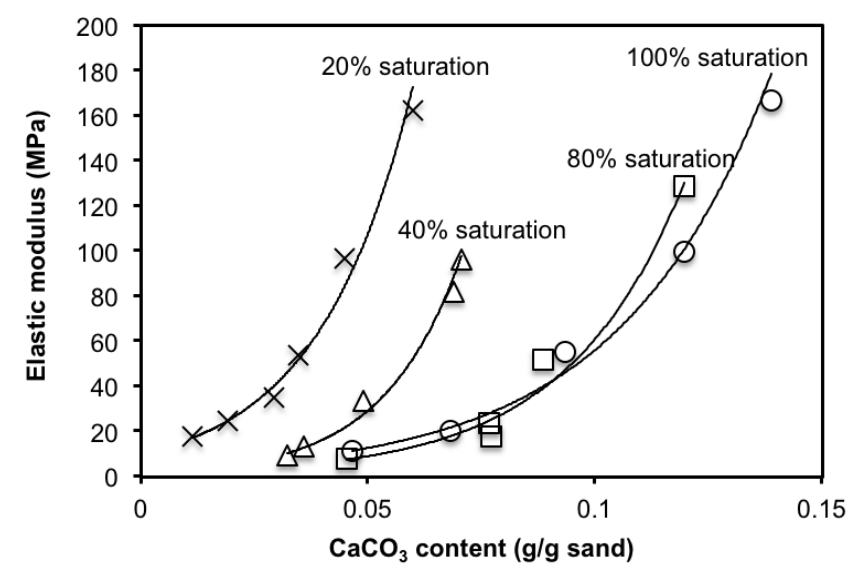


Fig. 4

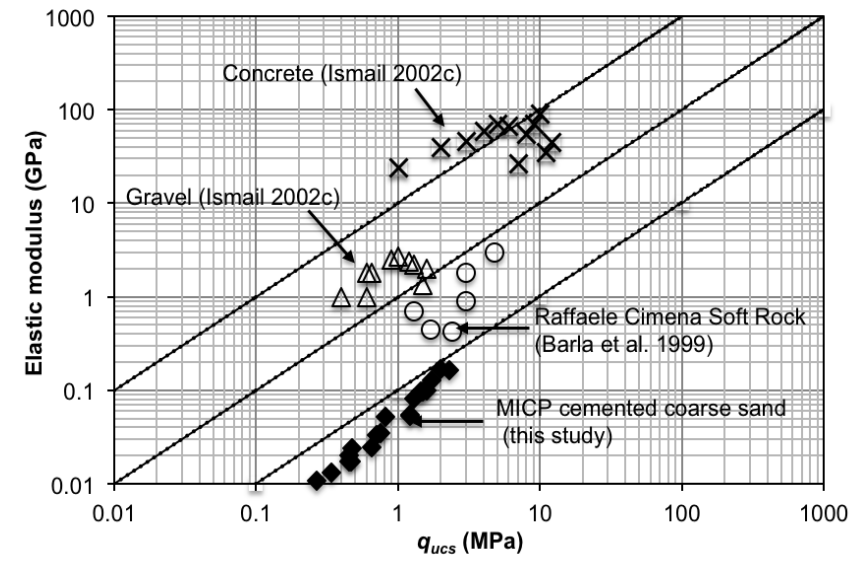


Fig. 5

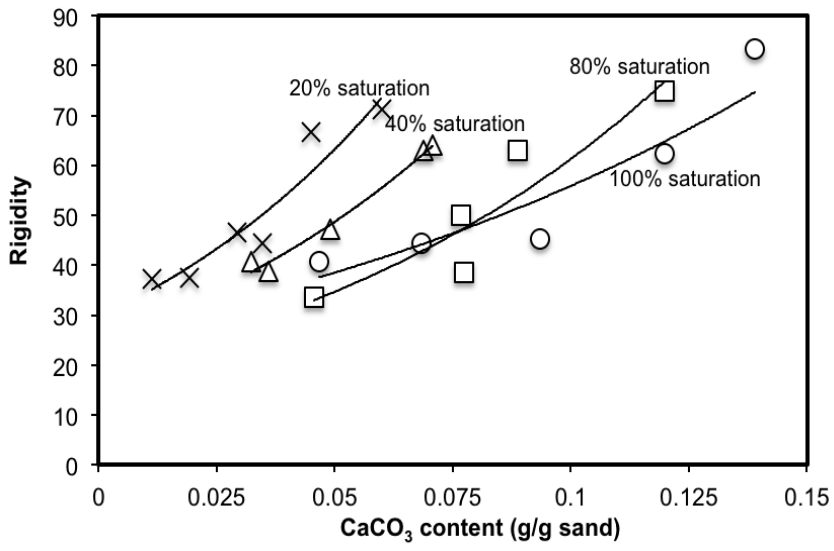


Fig. 6
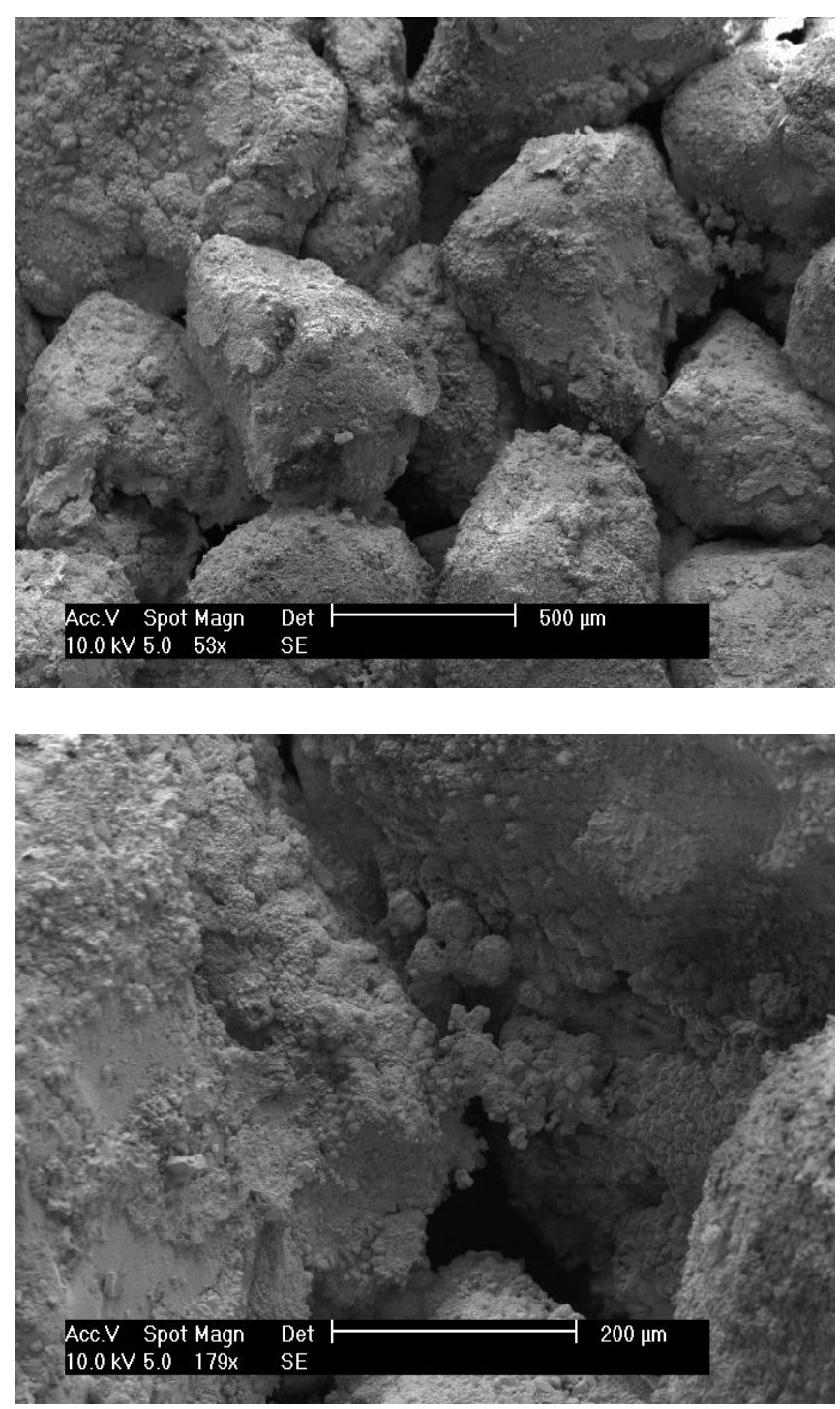
Fig. 7
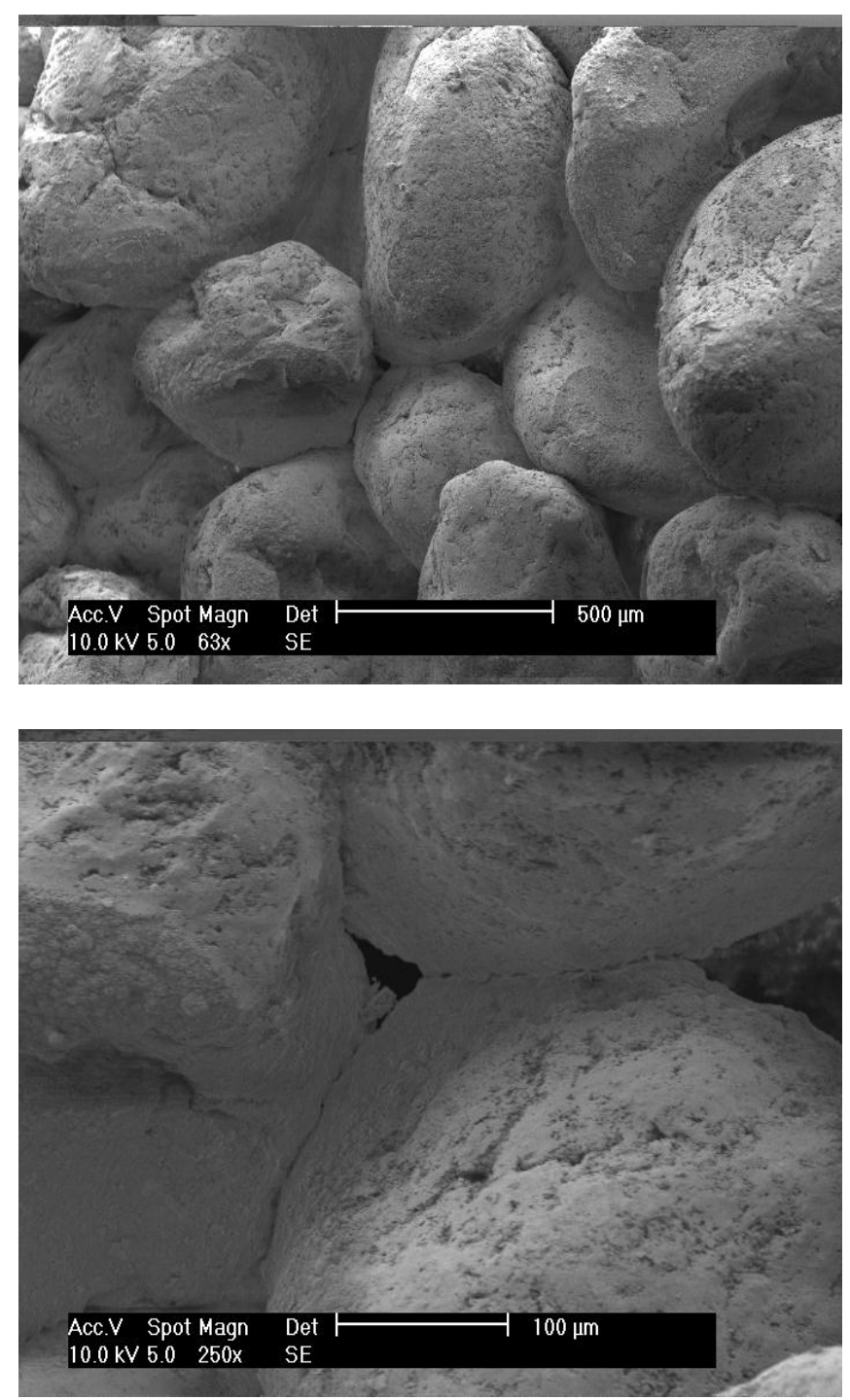
Fig. 8

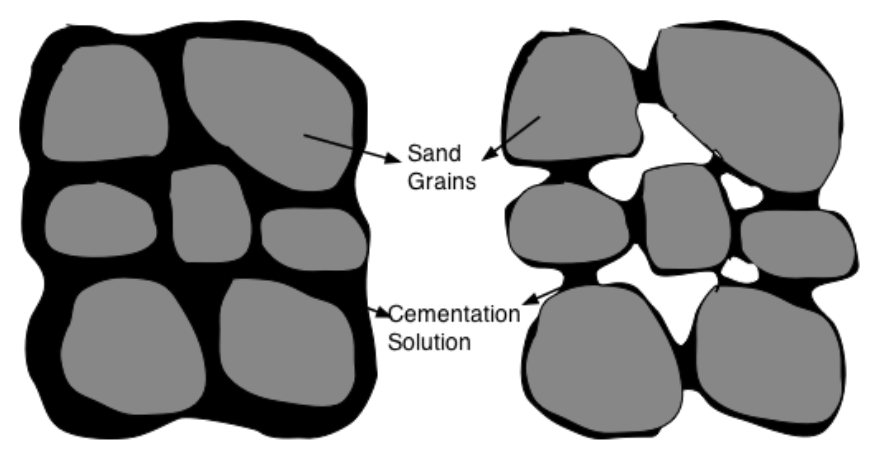

$100 \%$ saturation

$20 \%$ saturation 
Fig. 9

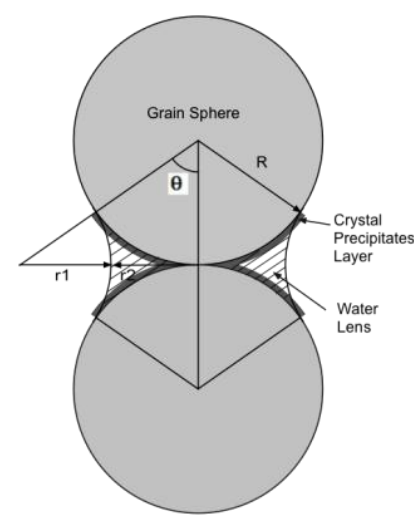

(a)

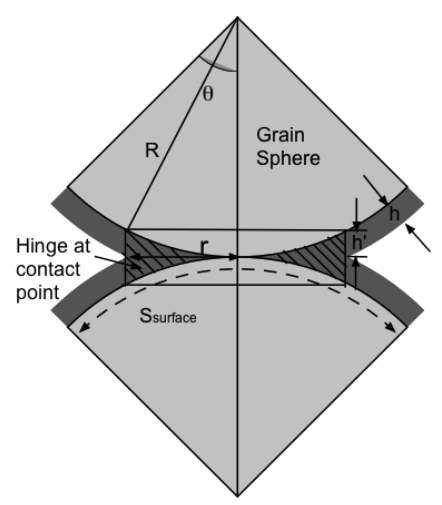

(b) 
Fig. 10

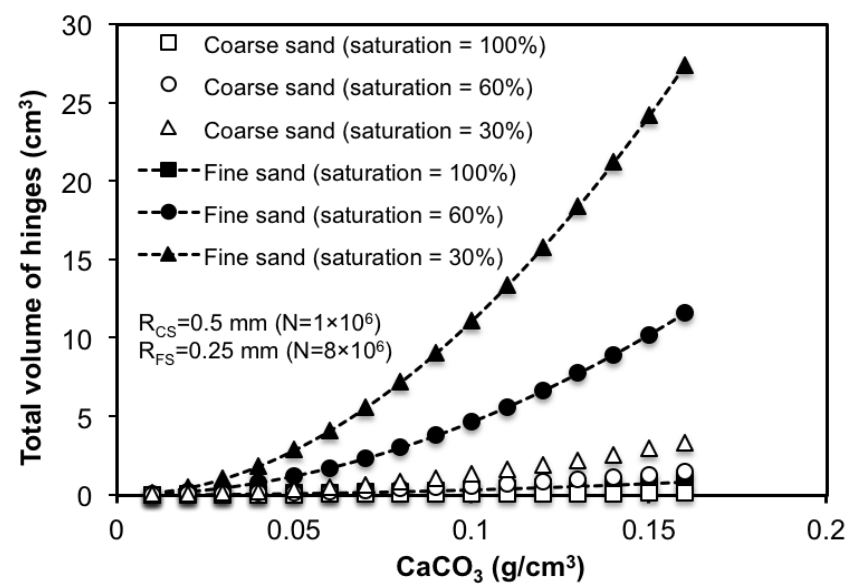


Fig. 11

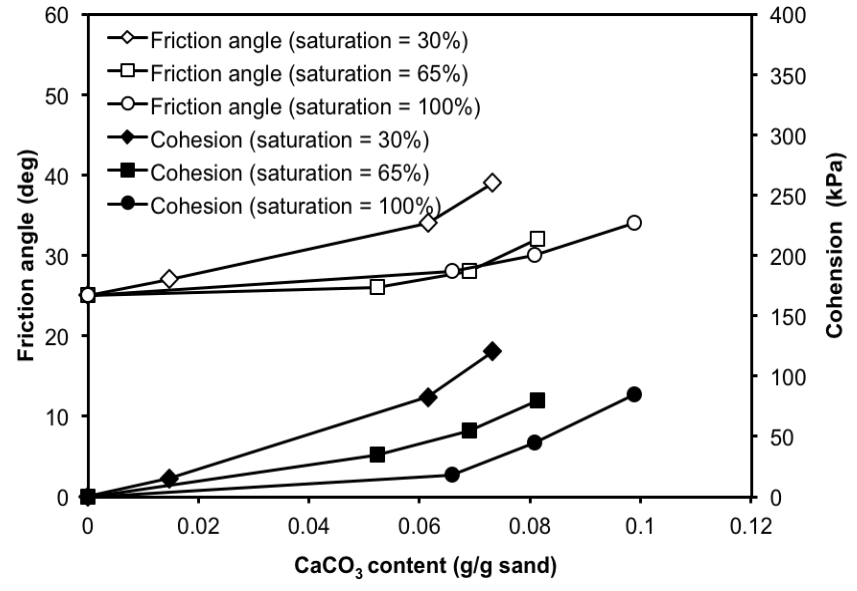


Fig. 12

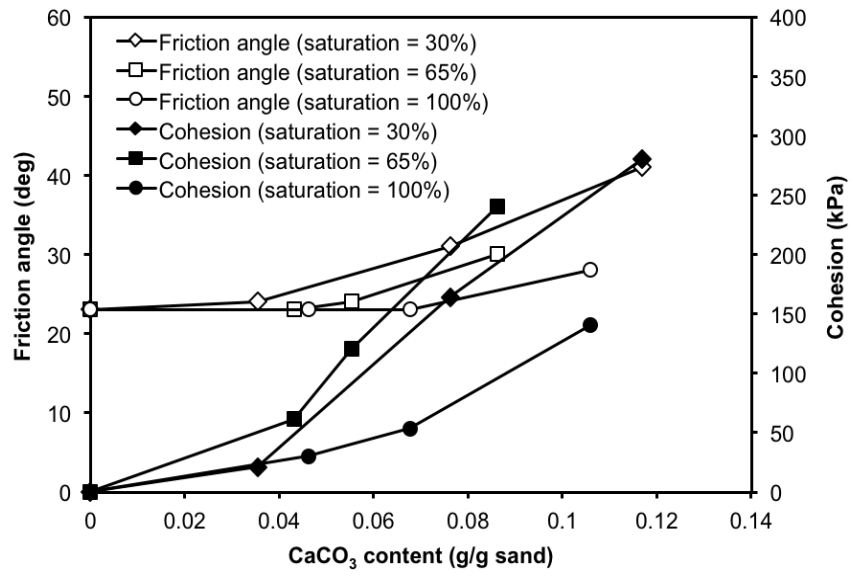


Fig. 13
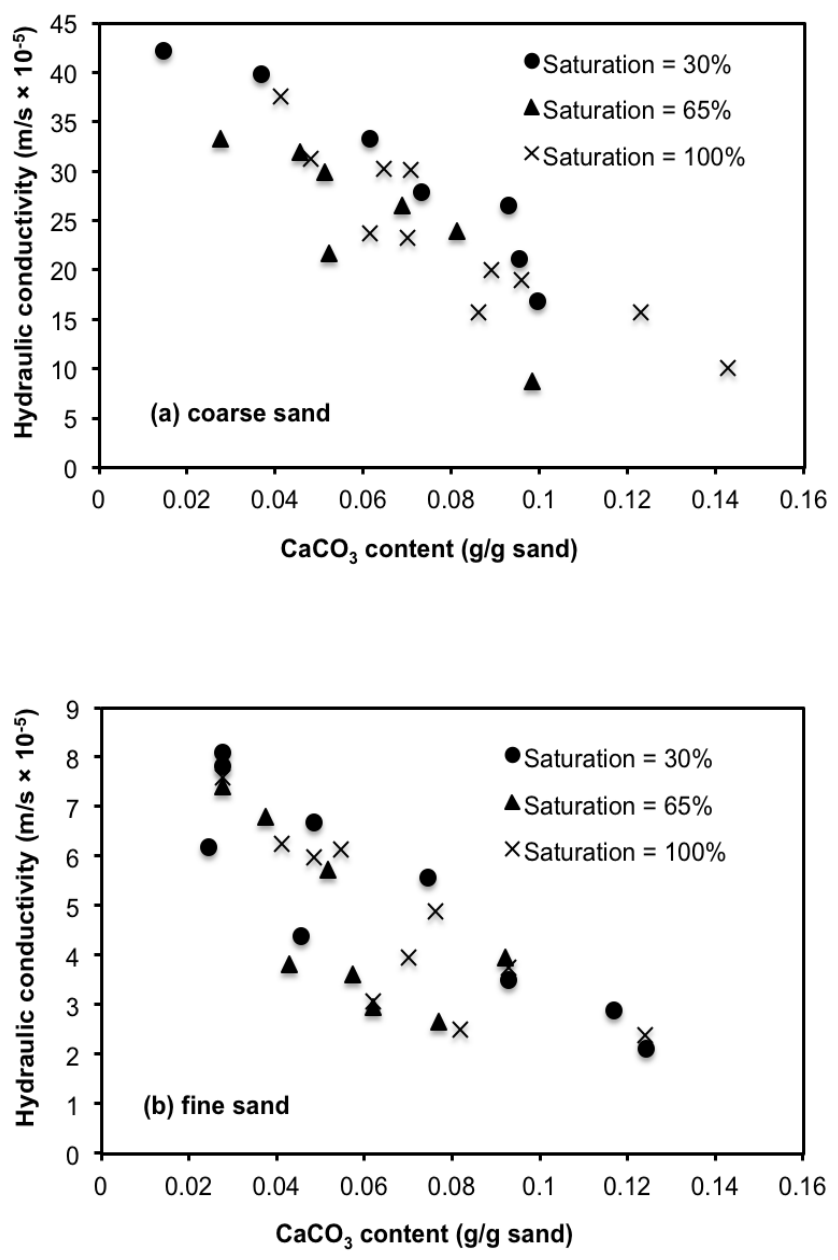
Fig. 14

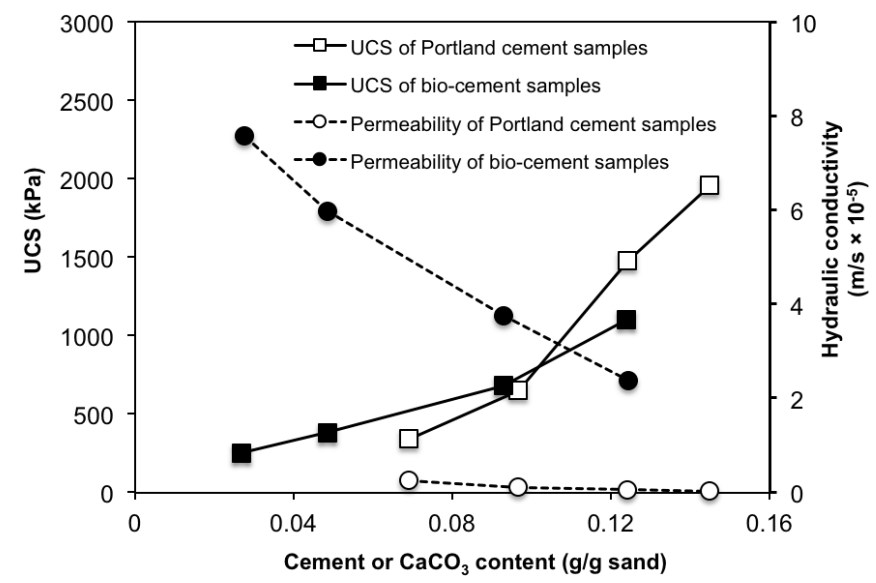


Fig. 15

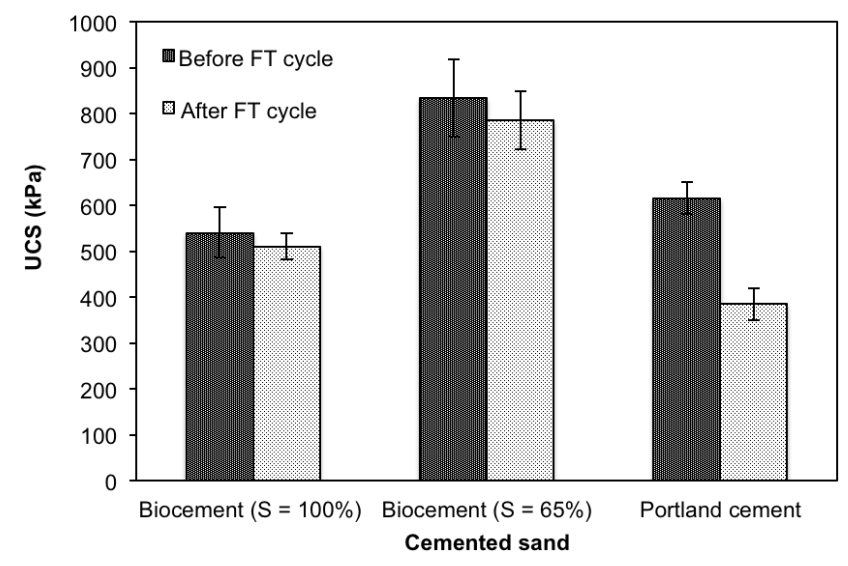


Fig. 16

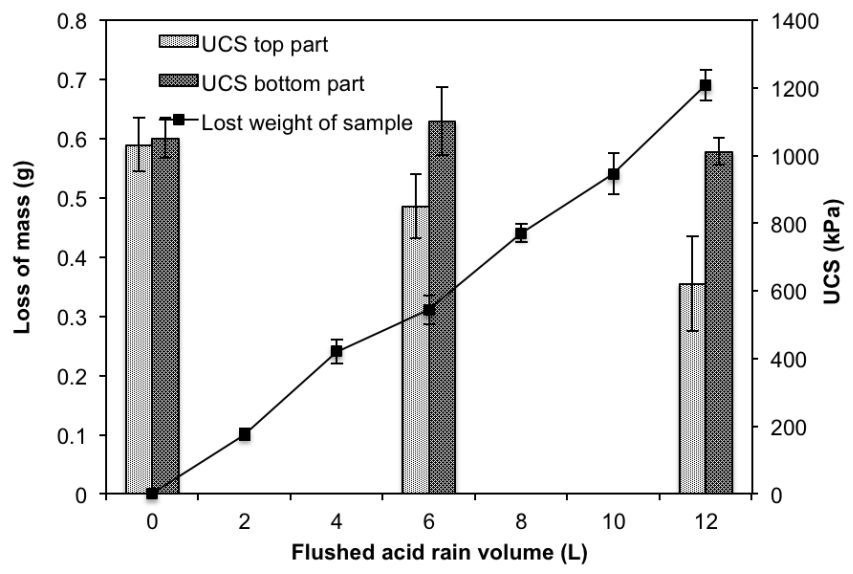


